\title{
Linguagem, Mente E InTEligênCIA ARTIFICIAL: UM ESTUdo SOBRE O PENSAMENTO DE JOHN SEARLE
}

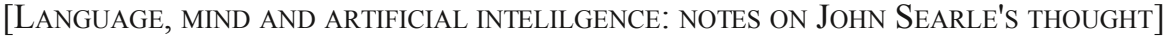

Daniel Artur Emidio Branco *

Universidade Federal do Ceará, Brasil

\begin{abstract}
Resumo: O presente artigo estudará o pensamento de John Searle sobre linguagem, mente a inteligência artificial. Ele será dividido em três seções, nas quais serão investigadas a crítica de Searle à Inteligência Artificial Forte mediante Argumento do Quarto Chinês, as críticas dos adversários de Searle ao Argumento do Quarto Chinês e, por fim, a influência de J. L. Austin sobre a filosofia da mente de serliana.
\end{abstract}

Palavras-chave: Inteligência; Mente; Consciência; Semântica; Linguagem
ABSTRAC: This article will study the John Searle's thinking about language, mind and artificial intelligence. It will be divided into three sections, in which will be investigated the Searle's criticism of the Strong Artificial Intelligence in connection with the Chinese Room Argument, then the criticism of the Chinese Room Argument by adversaries of Searle, and finally the influence of J. L. Austin on Searle's philosophy of mind.

KEYWORDS: Intelligence; Mind; Consciousness; Semantics; Language

\section{INTRODUÇ̃̃o}

Z ste artigo tem a finalidade de investigar a contribuição de John Searle (1932-

C) para o conhecimento da linguagem, da mente e da Inteligência Artificial. Para isso, estudará o chamado Argumento do Quarto Chinês e como ele se relaciona à noção de Inteligência Artificial Forte, além do conceito searliano de mente, intencionalidade e linguagem, abarcando, assim, ainda que sucintamente, um conjunto de ideias doutrinariamente interdependente. A primeira seção desse artigo focará na crítica do Argumento do Quarto Chinês à ideia de Inteligência Artificial Forte. A segunda seção lidará com a críticas dos opositores do Argumento do Quarto Chinês. A terceira e última seção investigará a filosofia da linguagem de Searle, bem como a sua interação com a sua filosofia da mente.

\section{O Argumento do Quarto Chinês (AQC) E O PROBlema da INTEligênCia ARTIFICIAL}

O exemplo proposto por Searle do Quarto Chinês questiona a Inteligência Artificial Forte (IA Forte). Os computadores têm intencionalidade? Searle responde

* Doutor e Mestre em filosofia pela Universidade Federal do Ceará - UFC. E-mail: darturemidio26@hotmail.com 
negativamente. O Argumento do Quarto Chinês (AQC), apresentado na obra de 1980 Behavioral and Brain Sciences, é uma hipótese na qual um homem trancado em um quarto sem saber chinês tem a seu dispor um livro na sua língua nativa onde está descrito um programa de computador para falar chinês, caixas com caracteres ou símbolos chineses e espaço para entrada e saída de inputs e de outputs. Por vezes são enviados símbolos à sala. Suponha-se que esses símbolos seja perguntas. $\mathrm{O}$ homem, utilizando-se do material a seu dispor no quarto, consegue dar resposta às pessoas de fora da sala. Ele consulta o livro, que é um programa de computador, e envia símbolos. Para quem está fora do quarto ele está falando chinês. No entanto, o homem não compreende o chinês. Os sinais externos da fala chinesa, expressos por ele, não implicam em conhecimento do que se diz. Nele não há intencionalidade. Passar no Teste de Turing não é sinônimo de compreensão. A sintaxe é insuficiente para a compreensão semântica. Com esse argumento, Searle busca refutar a tese de que os computadores compreendem a ação que praticam. Maxwell Filho afirma: "O argumento de Searle seria composto de quatro premissas e quatro conclusões14 derivadas destas. As premissas são:

P1) O cérebro causa a mente (tese da redução causal dos estados mentais a estados cerebrais, a qual é amplamente sustentada pelas evidências provenientes das neurociências); P2) A sintaxe não é suficiente para a semântica (essa premissa constitui uma verdade conceitual); P3) Programas de computador são totalmente definidos por sua estrutura formal ou sintática (essa premissa é verdadeira por definição); P4) A mente possui conteúdos semânticos (segundo Searle, isso é um fato óbvio)" (FILHO, 2010, p. 55).

Filho acrescenta:

Quatro conclusões são geradas a partir das premissas acima, quais sejam: C1) Nenhum programa é, por si mesmo, suficiente para produzir uma mente. Isto é, além de programas não serem mentes, eles não são suficientes, por si próprios, para gerarem uma mente (derivada de P2, P3 e P4); C2) O modo como o funcionamento cerebral causa a mente não pode ser unicamente em decorrência da implementação de um programa de computador (derivada de P1 e C1); C3) Qualquer coisa que cause uma mente tem que ter capacidades causais pelo menos equivalentes àquelas do cérebro (derivada diretamente de P1); C4) A implementação de um programa de computador não seria capaz de dotar, por si mesma, uma máquina de estados mentais semelhantes aos nossos, já que esta teria que ter capacidades causais equivalentes às capacidades do nosso cérebro (derivada de C1 e C3). ) (IBIDEM, 2010, p. 55).

Digno de nota é o argumento de Frank Jackson. Ele propõe a seguinte ilustração: Maria, que é uma neurofisiologista brilhante, é forçada a investigar o mundo mediante uma televisão em preto e branco. Ela obtém toda a informação necessária acerca de tomates maduros ou do céu azul, como combinações de comprimento de onda do céu estimulando a retina, ou tudo sobre como o sistema nervoso central para falar "o céu é azul" contrai as cordas vocais e expulsa ar dos pulmões. Jackson então pergunta: quando Mary sair do quarto ou receber uma televisão colorida, ela aprenderá mais alguma coisa sobre cores? A resposta de Jackson é sim. Mary nunca experimentou a cor. E o que falta à Mary não é físico, pois ela dispôs de todo aparato físico-cerebral para conhecer a cor. Jackson conclui: 1 - Mary (antes de sair do quarto) sabe tudo físico que é para saber sobre outras pessoas; 2- Mary (antes de sair do quarto) não sabe tudo o que é para saber sobre outras pessoas; 3- existem verdades sobre outras pessoas, e sobre 
ela mesma, que escapam ao fisicalismo (BORGONI, 2013, p. 50).

\section{OS DESAFIOS FRENTE Às OBJEÇÕES AO AQC}

Entre as objeções ao argumento searliano está a ideia de que não a CPU ou uma parte do sistema do computador que deve conhecer, mas o seu todo. Ora, o exemplo do homem trancado no quarto tocaria apenas em uma parte desse todo, e, portanto, era irrelevante para a questão da IA. Outra objeção é o argumento de que a questão central da IA é que complexidade de um computador pode criar a compreensão do chinês - o argumento de Searle seria superficial. Essa é a Resposta da Mente Virtual (RMV). Canal trata da ideia do "homúnculo" presente entre cognitivistas, e que é rejeitada por Searle:

Segundo Searle, os cognitivistas acreditam escapar da primeira da primeira dificuldade se utilizando de um estratagema que consistiria em tratar o cérebro como se houvesse algum agente dentro dele efetuando a computação: esse estratagema é denominado por Searle como a falácia do homúnculo. Essa falácia é vista por ele como endêmica porque é frequentemente utilizada por vários representantes do cognitivismo. Ao tentar propor a visão do cérebro como um computador digital dizendo que haveria um agente dentro que efetuasse a computação, Searle diz que fíca fácil de objetar essa ideia, porque é "como sair do fogo e pular na frigideira (CANAL, 2009, p. 179).

Uma terceira objeção é o argumento da resposta do robô. Conceba-se a ideia de um hambúrguer. Conceba-se ainda uma pessoa que tenha visto, feito, provado ou comido um hambúrguer. Em tal situação, a pessoa que fala a palavra "hambúrguer" não transmite apenas caracteres externos, mas tem a compreensão real do que seja um hambúrguer. Havendo a possibilidade da criação de um robô anexado a um corpo e de que este robô tenha todas as experiências humanas - desde a infância -, argumenta-se, ele poderia desenvolver a mesma compreensão da realidade que a experiência humana teve com caso do hambúrguer. Um quarto argumento é o do simulador de cérebro, no qual propõe a hipótese de que um simulador de cérebro realiza uma sequência de disparos nervosos da mesma forma que ocorre no cérebro de um nativo quando ele compreende chinês.

Minsky está relacionado à RMV (FILHO, 2010, p. 22). Ned Block possui o argumento chamado de Cabeça de Block (BLOCK, 2003), no qual imagina um número limitado de sentenças sintáticas e gramáticas e um computador programado para expressar todas essas possibilidades (sintático-gramáticas) para iniciar, continuar e terminar uma conversa (primeira sentença, segunda sentença etc., até a última sentença). Neste caso, o computador passaria no Teste de Turing. Block conclui que não há uma só estrutura interna capaz de gerar inteligência. Paul e Patrícia Churchland, materialistas eliminativos, imaginam um homem segurando um objeto com carga ou uma barra magnética e a agitando para cima e para baixo, de sorte que, de acordo com a teoria de Maxwell da luminosidade artificial, ele irá começar um ciclo de propagação de ondas, que será luminoso. No entanto, para que se veja tal luminosidade, esse homem teria que agitar a barra ou ímã 450.000 bilhões de vezes por segundo. Ora, malgrado a eletricidade e o magnetismo sejam forças, e a força, uma propriedade essencial da luz, ela não (a força) não constitui luz ou não é suficiente para tanto. Essas premissas são usadas para atacar os pilares do AQC: a) de sintaxe se compõe um sistema de computador; b) mentes têm conteúdo semânticos; c) sintaxe não é suficiente 
para constituir conteúdo semântico (CHURCHLAND, 1990). Jerry Fodor defende que as relações sintáticas podem, por assim dizer, imitar as relações semânticas. Fodor também se destaca pelo anti-holismo, uma visão assimétrica da teoria causal e a teoria causal crua. No conceito de language of thought hypothesis (LOTH), ele, por assim dizer, propõe que a mente possui uma sintaxe a ser estudada. Seria preciso conhecer os inputs e outputs existentes no cérebro. Já Donald Davidson se opõe à ideia de que a mente seja regulada por leis psicológicas e critica o conceito de linguagem comum a filósofos e linguistas. Assumindo uma posição denominada monismo anômalo e o conceito de superveniência, Davidson pensa que a relação mente-corpo deve ser explicada sem que para tanto acredite-se na existência de leis estritas que a determinem. Daniel Dennett, que nega a realidade dos qualia (BORGONI, 2013, p. 51) e defende um fisicalismo que dialoga com o darwinismo (o que é contraposto por Jaegwon Kim, que é crítico do fisicalismo não-reducionista (FILHO, 2010, p. 93), também se opõe AQC de Searle. David Chalmers, defendendo um "naturalismo dualista", elaborou o exemplo do mundo zumbis, que sendo logicamente possível, isto é, pensado em um mundo possível, provaria que os qualia não seriam reduzidos a estados cerebrais (IBIDEM, 2010, p. 70). Fred Dretske critica a posição de Searle sobre acerca da intencionalidade. Não há, segundo Dretske, estrita necessidade de intencionalidade no ato de ver, na percepção (SMITH, 2003, p. 154).

Searle rejeita o conceito de fantasma na máquina (crítica de Gilbert Ryle ao cartesianismo). Para ele, estudando o dualismo clássico, percebe-se a sua inaptidão para solucionar o problema da relação mente-corpo. Outras formas de dualismo (por vezes também chamadas de formas de monismo) também seriam falhas: o dualismo experiencial, o paralelismo psicofísico, o dualismo interacionista, a teoria do aspecto dual e o dualismo de propriedade - no qual estão incluídos o materialismo emergente, o epifenomenalismo, e o panpsiquismo. Tampouco um vago apelo ao monismo não resolve a questão. O behaviorismo, o emergentismo fraco, o materialismo eliminativo, o fisicalismo não-redutivo, a teoria da identidade e o funcionalismo são formas de monismo que não estão corretas de antemão, isto é, pelo simples fato de se oporem ao dualismo. Ora, o AQC tem sido criticado por diferentes opositores do dualismo. Searle é crítico de um certo tipo de monismo. Nos dois parágrafos antecedentes foram listados argumentos contrários ao AQC de autores que interagem com as duas escolas (dualismo e monismo). Searle rejeita todos. Ora, várias alternativas apresentadas à AQC em defesa da IA Forte pensam o computador como se houvesse dentro dele um homúnculo que pudesse conduzi-lo. Também querem reduzir a semântica à sintaxe, ou redefinir a sintaxe de modo que ela, o cérebro e o computador sejam entendidos sem o apelo à intencionalidade - inclua-se já aqui a argumento da Cabeça de Block. É dessa forma que a objeção de que Searle encarara o computador mais como uma CPU do que como um todo, a RMV, o simulador de cérebro e o argumento do robô falham em responder à AQC. Como afirma Lyra:

Searle (2010), há basicamente dois modos diferentes de realizar uma investigação científica da consciência. A primeiro parte da ideia de que "o campo consciente é constituído de pequenos componentes que se combinam para formá-lo" [...] Em outras palavras, o campo da consciência seria dividido em várias partes (a experiência visual, auditiva, motora etc). Assim, se há um correlato neural da consciência $(\mathrm{CNC})$ relativo à experiência visual, também haveria um $\mathrm{CNC}$ relativo às outras modalidades sensoriais. Trata-se da teoria dos blocos de construção (the building block theory). Por sua vez, o segundo modo de realizar um estudo científico da consciência utiliza uma abordagem que a considera como 
um campo unificado (the unified field theory). Esta abordagem se diferencia da primeira na medida em que, para qualquer modalidade específica vivenciada por um sujeito (a experiência visual, auditiva, motora etc.), esse mesmo sujeito já se apresentaria como alguém consciente desde o princípio, sendo cada experiência vivenciada em sua modalidade apenas uma modificação do campo unificado da consciência [...][ Searle]comenta que a teoria dos blocos de construção pode ser encontrada nos trabalhos de Francis Crick (e seus colaboradores). A partir do estudo de fenômenos como a visão cega e a rivalidade binocular, como também da investigação acerca dos correlatos neurais da visão, os defensores de tal teoria acreditam poder corroborar a hipótese de que o campo da consciência consiste numa ligação de vários estados de consciência, ou micro-consciências. (LYRA, 2016, p.12).

Tratando dos Churchland, Searle rejeita que a eletricidade e o magnetismo não sejam constitutivos da luminância. Se Fodor, associado ao funcionalismo, não consegue com o LOTH e o estudo da sintaxe eliminar o problema da necessidade semântica, como requerida pelo $\mathrm{AQC}$, tampouco Donald Davidson consegue refutar a existência das relações causais, ou de leis "rígidas", que regram a semântica e a sintaxe. Semântica, conteúdo e intencionalidade e regras são requeridas para que a mente humana seja distinguida da máquina, bem como seja consciente. A negação dos qualia por Dennett e o argumento do zumbi, de Chalmers, também não destroem o AQC. Ora, $\mathrm{O}$ primeiro não dá provas empíricas de que a mente existe sem os qualia. Sem os qualia, os homens seriam, de fato, zumbis inconscientes - tratando sobre os qualia, V. S. Ramachandran sustenta, pelo estudo da sinestesia, que o cérebro de Mary, mesmo que visse tudo em preto e branco, poderia distinguir uma maçã vermelha de uma maçã pintada de cinza (RAMACHANDRAN, s/d, p. 71). O segundo, Chalmers, deixaria mais confuso do que explicado a relação mente-corpo. Explicar a consciência da dor sem intrínseca necessidade de implicações neurofisiológicas, em uma proposta panpsiquista, seria um erro. Zumbis precisariam de consciência, e esta não pode ser de alguma forma "alheia" à percepção sensorial. Por assim dizer, faltaria mais embasamento empírico para Dennett e maior embasamento metafísico para Chalmers - à semelhança de John Haugeland, Edward Feser defende que Searle é um dualista. Neste caso, Feser associa Searle ao dualismo de propriedade (FESER, 2016, p. 491). De acordo com Searle:

Existem muitas discussões sobre o argumento dos zumbis. Uma resposta é apenas
negar que zumbis que se comportam exatamente como nós, mas sem vida mental,
são concebíveis. Isso não parece uma estratégia muito promissora, porque
intuitivamente parece muito fácil imaginar uma máquina que é exatamente como
eu, mas sem consciência. Daniel Dennett apoia a estratégia com a seguinte
analogia. Suponha que alguém disse que há barras de ferro que se comportam em todos
os aspectos exatamente como ímãs, mas não são ímãs, são zagnets. Tal coisa é inconcebível,
porque, diz Dennett, os zagnets seriam apenas ímas. Analogamente, uma máquina que se
comporta em todos os aspectos como um agente consciente é um agente consciente. Zagnets
são ímas e zumbis são agentes conscientes. Essa analogia não funciona. Uma descrição
adequada de um zagnet implicará que é um imã, mas nenhuma descrição em terceira pessoa
de um sistema físico implicará que ele tenha estados conscientes porque há dois fenômenos
diferentes, as estruturas comportamentais, funcionais, neurobiológicas em terceira pessoa e
a experiência consciente em primeira pessoa. (SEARLE, 2004, p. 102).

E quanto à objeção de Dretske? Searle é conhecido pelo naturalismo biológico, que preza pela boa interação entre a filosofia da mente e a neurobiologia. A consciência 
e o cérebro têm uma relação real. Por exemplo, a córtex cerebral dá resposta aos estímulos visuais presentes no meio ambiente. A dor é por processo neurofisiológicos ocorridos no córtex sensorial e no tálamo Entretanto, não é necessário que "apenas" o cérebro cause a consciência (LYRA, 2016, p.13). Assim, estudo mais profundo da neurobiologia pode a ajudar a filosofia da mente, bem como a filosofia da mente pode ser útil à neurobiologia. A consciência e a intencionalidade não são, no pensar searliano, autônomas em relação à percepção nem reduzidas a uma observação ou representação externa. Portanto, o argumento de Dretske de que, sendo a fotografia causada por um objeto, semelhante causação deveria bastar para a percepção, não é suficiente para Searle. Para haver intencionalidade é preciso conteúdo. Uma pintura feita por um artista e uma simples imagem de foto são coisas diferentes. Uma mera cadeia causal não implica em experiência com conteúdo intencional. Além do mais, a foto só é foto porque alguém teve intencionalidade ao tirá-la.

\section{J. L. Austin, os atos de Fala e a interaÇão entre A Filosofia ANALítica E A FILOSOFia da MENTE de SEARLE}

A pesquisa de Searle também abrange a filosofia analítica e a filosofia da linguagem. Para tanto, foram importantes as suas obras Speech Acts, de 1969, e A Taxonomy of Illocutionary Acts, de 1979. No entanto, para se compreender a concepção de linguagem searliana, faz-se mister o conhecimento da Teoria dos Atos de Fala de J. L. Austin presente na obra How to Do Things with the World. Para Austin, esses atos podem ser locucionários, ilocucionários e perlocucionários. Nos primeiros se diz algo, ou melhor, os primeiros, locucionários, são atos que propriamente dizem alguma coisa, no sentido sintático da linguagem. Os segundos fazem alguma coisa, ou realização ação, ao dizerem algo. Os terceiros, por seu turno, provocam reações nos ouvintes. Alguma consequência em que escuta é provocada. Austin rejeita a distinção entre enunciados constativos e performativos. Todos os atos performam alguma coisa. É aí que se desenvolve a Teoria dos Atos de Fala. Ela questiona o então vigente critério de verdade e falsidade das proposições. Danilo Marcondes comenta sobre do ato indireto de fala que aí surge:

O conceito de ato de fala indireto (Searle, 1979) pode nos oferecer elementos para isso, ao mostrar que os atos de fala são, em sua maior parte, indiretos ou implícitos, e isso ocorre simplesmente porque não é necessário que sejam explícitos. O exemplo dado é o de um colega que diz para o outro: "Há um bom filme no cinema da esquina", ao que o outro responde: "Tenho prova de matemática amanhã". E óbvio que no caso do primeiro proferimento (explicitamente um declarativo, segundo a classificação de Searle), temos implicitamente um convite, que é como o colega efetivamente interpreta este ato, respondendo, por sua vez, também por meio de um constatativo, ou declarativo explícito, de modo a recusar o convite. Contudo, os performativos explícitos, "Eu o convido..." e "Eu recuso o seu convite...", em nenhum momento foram proferidos, e na verdade isso sequer precisaria ocorrer. Como, então, podem ser entendidos como possuindo a força ilocucionária respectivamente do convite e da recusa? Funcionam basicamente através de elementos contextuais e de pressupostos compartilhados por falante e ouvinte enquanto participantes do mesmo jogo de linguagem e, desse modo, familiarizados com as crenças, hábitos e práticas um do outro. (MARCONDES, 2006, p. 228).

Searle diz: 
O problema colocado pelos atos de fala indiretos é o problema de como é possível para o falante dizer uma coisa e sinigficar isso, mas também significar outra coisa. E como o significado consiste em parte na intenção de produzir compreensão no ouvinte, grande parte desse problema é de como é possível ao ouvinte compreender o ato de fala indireta quando a sentença que ele ouve e compreende significa outra coisa. O problema se torna mais complicado pelo fato de algumas sentenças parecerem quase convencionalmente usadas como solicitações indiretas. Por uma frase como "Você pode alcançar o sal?" ou "Eu agradeceria se você tirasse o pé", é preciso alguma ingenuidade para imaginar uma situação em que suas elocuções não seriam solicitações. (SEARLE, 2004, p. 31.

Searle reconhece que o conceito de ato ilocucionário precisa ser melhor definido. Para dar conta desse problema, Searle propõe que atos de linguagem sejam divididos em assertivos, que afirmam, diretivos, que ordenam, comissivos, que prometem, os expressivos, que felicitam, e os declarativos, que declaram (IBIDEM, 2006, p. 226).

Mas o que isso tem a ver com a filosofia da mente de Searle? Para desenvolver a sua filosofia da linguagem, Searle defende alguns pontos importantes. Ele defende a existência do mundo fora da mente, a percepção desse mundo mediante os sentidos, a falsidade ou veracidade das afirmações em relação aos fatos do mundo e a relação causa-efeito entre coisas e estados de coisas no mundo. Daí ele desenvolve a ideia de rede e de background, que envolve, por assim dizer, o cenário não intencional, implícito e indireto - e aqui noção de ato de fala indireto de Paul Grice também se faz importante-, no qual a intencionalidade se dá, e que aproxima mente e linguagem. Lyra acrescenta:

Além dos estados mentais conscientes e inconscientes, Searle defende a existência de "capacidades, aptidões e know-how geral que possibilitam que nossos estados mentais atuem" [...], o que ele chama de Background. Portanto, apesar de ser não-intencional, o conjunto de capacidades de Background permite que os estados mentais intencionais ocorram. Outra característica do Background é que esse consiste em "um conjunto de capacidades não-representativas" [...], embora seja fundamental para que as representações possam atuar enquanto linguagem, pensamento ou experiência. Em outras palavras, a condição de satisfação de um estado intencional é sempre relativa a um determinado conjunto de capacidades de Background [...]Embora um estado intencional, como um desejo ou uma crença, apresente-se sempre relacionado com o Background, há também outra condição de satisfação para que ocorra um estado intencional: a existência de "uma completa Rede de outras crenças e desejos" [...] Portanto, a diferença entre Rede e Background é que a primeira é sempre uma rede de estados intencionais ou de representações, enquanto o segundo envolve um conjunto de capacidades não-intencionais e não-representativas. Contudo, em última instância, "a Rede é aquela parte do Background que descrevemos em termos de sua capacidade para causar intencionalidade consciente" (LYRA, 2016, p. 13).

Segundo o pensar searliano, a proposição pode alterar o mundo como ser alterada pelo mundo. Além disso, pode não haver alteração nesta relação como ambos, proposição e mundo, podem ser alterados juntamente. Assim, ao se aproximar da visão descritivista dos nomes próprios, Searle rejeita a posição milliana, associada a Teoria da Referência Direta, de que os nomes próprios não têm conotações ou sentido, mas apenas denotações, e se afasta da posição de Frege, Kaplan, Russell, Strawson e de Kripke, que veem os nomes próprios como designadores rígidos. Ora, na sua versão dos 
descritivismo, conhecida como versão Cluster, Searle argumenta, ao contrário do que pensa Kripke, que qualquer descrição bem definida pode ser um designador rígido. Aqui vê-se mais uma vez uma ampliação da relação mundo, a intencionalidade e linguagem, na qual IA, como afirmado no início deste artigo não participa.

\section{Conclusão}

O trabalho de John Searle sobre a mente, a linguagem e a intencionalidade bem como a sua crítica à Inteligência Artificial Forte é atual e bastante estudado no mundo filosófico contemporâneo. Searle soube unir diferentes campos dentro da filosofia e torná-los um conjunto coeso para a elaboração de uma argumentação relevante. Não apenas o AQC, ou a resposta dada aos diferentes críticos deste argumento, mas também a sua teoria da linguagem e a sua contribuição para a Filosofia Analítica encontram leitores e comentadores em diferentes partes do mundo filosófico. Este artigo, sabendo da necessidade desse debate na academia atual, buscou contribuir nesse quesito. Para tanto, uniu a crítica do AQC ao IA Forte à visão searliana da mente, da intencionalidade e da linguagem.

\section{REFERÊNCIAS}

BORGONI, Daniel. Uma Análise do Argumento do conhecimento de Frank Jackson. Kínesis, Vol. V, n 09, Julho 2013, p. 47-61.

CHALMERS, David. 'Consciousness and the Philosophers': An Exchange. David J. Chalmers, reply by John $R$. Searle. In response to: Consciousness \& the Philosophers from the March 6, 1997 issue.

CANAL, Rodrigo. Quatro objeções de John Searle ao cognitivismo. Kínesis, Vol. I, $\mathrm{n}^{\circ}$ 01, Março-2009, p.171-185.

FESER. Edward. From Aristotle to John Searle and Back Again: Formal Causes, Teleology, and Computation in Nature. Nova et Vetera, English Edition, Vol. 14, No. 2 (2016): 459-494.

FILHO, Maxwell. O Experimento de Pensamento do Quarto Chinês: a Crítica de John Searle à Inteligência Artificial Forte. Argumentos, Ano 2, No. 3 - 2010.

FILHO, Maxwell. Maxwell. Naturalismo Biológico: a solução dualista de John Searle para o problema mente-corpo. Dissertação apresentada ao Curso de Mestrado em Filosofia da Universidade Federal do Ceará. Fortaleza, 2010.

GUIMARÃES, André. Uma reposta funcionalista ao Argumento do Quarto Chinês de Searle. COGNITIO-ESTUDOS: Revista Eletrônica de Filosofia São Paulo, Volume 7, Número 2, julho - dezembro, 2010, pp. 132-140.

LYRA, Carlos. O Naturalismo Biológico de Searle e a Relação Mente-cérebro. Psicologia: Teoria e Pesquisa Jan-Mar 2016, Vol. 32 n. 1, pp. 7-15.

MARCONDES, Danilo. A Teoria dos Atos de Fala como concepção pragmática de linguagem. Filosofia Unisinos 7(3):217-230, set/dez 2006.

RAMACHANDRAN, V. S. O que o cérebro tem para contar: Desvendando os mistérios da natureza humana. Trad. br. Maria Luiza X. de A. Borges. Ler Livros, São Paulo, s/d.

SEARLE, John. Expression and Meaning: Studies in the Theory of Speech Acts. Cambridge University Press, IK, 2005.

SEARLE, John. SEARLE. Mind: A Brief Introduction. Oxford University Press, Oxford, 2004.

SMITH, Barry. John Searle. Cambridge University Press, UK, 2003. 